\title{
Vulvar Apocrine Adenocarcinoma
}

National Cancer Institute

\section{Source}

National Cancer Institute. Vulvar Apocrine Adenocarcinoma. NCI Thesaurus. Code C40308.

An apocrine adenocarcinoma that arises from the sweat glands in the vulva. 